\title{
CRENÇAS, CONFLITOS E A (RE)CONSTRUÇÃO DA IDENTIDADE DE DOCENTES DE LÍNGUA INGLESA DO SUDOESTE DO PARANÁ
}

\author{
Daiane da Silva LOURENÇO \\ Universidade Tecnológica Federal do Paraná \\ Priscila LAURINDO \\ Secretária de Estado da Educação do Paraná
}

RESUMO: Esta pesquisa objetiva analisar dados coletados a partir de um curso de formação continuada com professores de inglês de escolas públicas do Paraná. O curso foi desenvolvido todo em língua inglesa a pedido dos participantes e um questionário aberto foi aplicado ao final a fim de compreender o interesse em praticar a oralidade e a compreensão oral em inglês ao invés de estudar teorias linguísticas. A análise dos dados evidencia crenças implícitas nas práticas dos docentes acerca do ensino de inglês, conflitos gerados em sala de aula e a relação entre a falta de fluência na língua-alvo e a crise de identidade profissional docente. Também mostra que a representação do professor de inglês é resultado, em parte, de crenças da comunidade e do próprio profissional sobre o que se espera de um docente. A produção oral é vista como forma de autoafirmação da identidade do docente de língua inglesa, isto gera conflitos sobre o que se espera, o que está especificado para ensinar e o que realmente ocorre na rede de ensino. Esta realidade evoca questionamentos que afetam a autoestima do professor e a prática em sala de aula. Tanto a identidade quanto as crenças estão sempre em processo de construção e reconstrução, recebendo diversas influências que repercutem no fazer docente. É importante que o docente tenha consciência de suas crenças e construção identitária para que reflita sobre suas ações e modifique sua forma de ensinar inglês.

PALAVRAS-CHAVE: professores de língua inglesa; crenças; identidade profissional docente.

ABSTRACT: This research aims to analyze the data collected from a continuing education course with English teachers from public schools in Paraná. The course was developed in English due to the request of the participants and na open questionnaire was applied in order to understand the interest in practicing speaking and listening in English rather than studying linguistic theories. Data analysis shows implicit beliefs in English classroom teaching practices, conflicts generated in the classroom and the relation between lack of fluency in the target language and the crisis of teacher professional identity. It also shows that the representation of the English teacher is partly a result of the school community beliefs ando $f$ the professional himself about what is expected of a teacher. Speaking English is seen as a form of self-assertion of the teacher's identity, which creates conflicts over what is expected, what is specified to teach and what actually occurs in the education network. This reality evokes questions that affect teacher's self-esteem and classroom practice. Both the identity and the beliefs are always in the process of construction and reconstruction, receiving various influences that have repercussions on the teaching profession. It is important that the teacher is aware of his beliefs and identity construction so that he reflects on his actions and modifies his way of teaching English.

KEYWORDS: English teachers; beliefs; teacher professional identity.

\section{Introdução}


A prática docente em sala de aula é permeada por diversos fatores explícitos e implícitos. Entre os explícitos estão condições de trabalho, comunidade escolar, salário, diretrizes para a educação, entre outros visíveis e com os quais o professor precisa aprender a lidar ao longo de sua carreira docente. Há também os implícitos, dos quais muitas vezes os envolvidos no processo de ensino-aprendizagem não têm consciência, mas que são importantes por influenciar a prática do professor em sala de aula. Neste trabalho abordaremos as crenças e a identidade profissional docente e alguns conflitos que podem surgir diante do choque de perspectivas em sala de aula.

A pesquisa resulta de um curso de formação continuada desenvolvido com professores de inglês de escolas públicas do Paraná. Ao serem questionados acerca dos interesses de estudo durante o curso, o grupo de professores sugeriu um foco na prática da oralidade e da compreensão oral. Os dados coletados e analisados após o curso revelaram crenças a respeito do ensino-aprendizagem de língua inglesa em escolas públicas e o questionamento da identidade profissional do professor de inglês que não demonstra habilidade oral na línguaalvo, seja por parte da comunidade escolar ou dos próprios professores.

Na primeira seção deste trabalho fazemos uma introdução sobre o curso desenvolvido, seus participantes e os motivos para a abordagem de crenças, conflitos e identidade profissional do professor de inglês. Na segunda seção desenvolvemos o conceito de crenças e analisamos algumas respostas dos participantes que evidenciam suas principais crenças sobre ensinar inglês. Em seguida, explicamos identidade profissional a partir de uma perspectiva social, suas implicações para o ensinar línguas e interpretamos respostas dos professores que revelam a relação entre fluência na língua-alvo e afirmação da identidade profissional.

\section{Crenças, conflitos e identidade profissional do docente}

Este trabalho é resultado de uma pesquisa realizada com docentes de língua inglesa do Núcleo Regional de Francisco Beltrão, participantes de um projeto de extensão com foco na formação de professores. O projeto de extensão foi desenvolvido ao longo dos meses de março a novembro de 2014, com duração de sessenta horas, e objetivou ser uma oportunidade de formação continuada aos docentes da região. O curso iniciou sem um conteúdo específico e as organizadoras questionaram os professores acerca de seus interesses de estudo. Como respostas os participantes afirmaram a necessidade de praticar a oralidade e a compreensão oral em inglês e trocar experiências sobre o ensino da língua-alvo na educação básica, em seus diferentes níveis.

Diante disso, o curso foi conduzido em língua inglesa, buscando responder aos interesses dos professores, com atividades de discussões teóricas e sobre práticas em sala de aula, e com as organizadoras tendo papel de facilitadoras do processo. Ao final do curso, foi aplicado um questionário aberto com o intuito de compreender porque os professores participantes do curso optaram por focar na prática da oralidade e da compreensão oral. Dos seis participantes, quatro contribuíram respondendo ao questionário. As respostas evidenciaram questões relacionadas a crenças sobre o ensino-aprendizagem da língua-alvo e a identidade profissional do docente de língua inglesa, além de alguns conflitos que surgem a partir de diferentes opiniões sobre o que é ensinar e aprender inglês em escolas públicas. 
As crenças e as identidades são construtos sociais dinâmicos e podem influenciar professores, alunos e a comunidade escolar. Para Lima (2012), identidade, crença e contexto são fatores que estão relacionados e formam o que somos, de onde viemos e consequentemente no que acreditamos. Assim, são a base de aspectos que constituem o processo de aprender uma nova língua. Lima (2012) afirma que as crenças têm potencial de mediação na sala de aula, direcionando as atividades de aprender e ensinar línguas, pois resultam das escolhas dos professores e dos estudantes. Elas podem explicar as decisões dos professores e dos estudantes e suas ações em contextos específicos. Enquanto as crenças revelam o olhar dos sujeitos sobre o processo de ensinar e de aprender línguas, as identidades profissionais são construídas a partir do modo como as pessoas olham para determinada profissão. As identidades docentes dependem do julgamento dos estudantes, da comunidade escolar e do próprio professor sobre sua prática. A identidade constitui-se frente aos olhares dos outros, no social e na cultura (SILVA, 2011). Dessa forma, o processo de ensinoaprendizagem de inglês pode ser afetado pelas crenças dos professores envolvidos e também por suas identidades profissionais.

Os conflitos podem surgir quando no processo os sujeitos envolvidos se deparam com situações não esperadas que contradizem suas crenças e expectativas do que é ensinar e aprender uma língua estrangeira. Para Quadros et al. (2006), conflitos surgem quando o imaginário sobre as relações em sala de aula entra em conflito com a realidade escolar. Diante disso, percebemos que as crenças dos professores e o que reconhecem como sua identidade profissional podem gerar conflitos pelo fato de entrarem em contato com as crenças da comunidade escolar e com a forma como esses sujeitos veem a identidade docente.

Nas próximas seções abordaremos os conceitos de crenças e de identidades profissionais docentes e faremos uma análise dos dados coletados. Para tanto, apresentamos aqui os perfis dos participantes da pesquisa: Ana tem quatro anos de experiência em cursos de idiomas e quatro anos de experiência em escolas públicas; Paulo tem onze anos de experiência em escolas públicas, atuando no Ensino Fundamental e Médio; Daniela tem treze anos de experiência em escolas públicas, no Ensino Fundamental e Médio e dez anos de experiência em cursos de idiomas e escolas particulares; Letícia tem trinta anos de experiência em escolas públicas, no Ensino Fundamental e Médio e Educação de Jovens e Adultos (EJA). Todos são professores de inglês do Núcleo Regional de Francisco Beltrão, no Paraná. Os nomes utilizados são fictícios.

\section{Crenças dos docentes}

Para Barcelos (2001) o estudo das crenças é relevante devido a sua influência na abordagem de aprender dos estudantes ou de ensinar do professor. Neste trabalho, como nossos participantes de pesquisa são docentes, focaremos nas crenças de professores. As crenças são consideradas opiniões e ideias que professores têm a respeito dos processos de ensino-aprendizagem de línguas. Como dependem das experiências do sujeito e do contexto, as crenças são variáveis, mutáveis, estão sendo sempre construídas e revistas, podem ser modificadas ao longo da prática docente, de uma época para outra, de um contexto para outro, ou até mesmo dentro de um mesmo contexto (BARCELOS, 2001). Silva (2007) acredita que na maioria das vezes as crenças são implícitas e muitos professores não têm consciência da relação existente entre suas ações e suas crenças. 
Não há uma definição consensual sobre o que são crenças, mas para Barcelos (2004), no caso da aprendizagem de línguas, é o que o sujeito considera que é linguagem e aprendizagem em um contexto específico, resultado de experiências pessoais e em grupo. As crenças do professor também são influenciadas por teorias sobre ensino de línguas, ainda que ele não tenha consciência de tal influência sobre sua prática.

Segundo Lima (2012), é importante considerarmos as percepções dos envolvidos no processo de aprendizagem de uma nova língua e suas experiências pessoais, pois elas influenciam as escolhas e ações dos professores ao ensinarem uma língua estrangeira. As crenças influenciam no comportamento dos sujeitos (BARCELOS, 2001), por isso contribuem para o professor decidir a abordagem que utilizará em sala de aula.

Ao analisarmos os dados coletados, evidenciamos como principais crenças dos participantes: a) o professor de inglês deve ser fluente na língua-alvo; b) um professor fluente em inglês demonstra conhecimento do conteúdo da disciplina, segurança, confiança; c) a disciplina de inglês é desvalorizada pela comunidade escolar; d) não se aprende a falar inglês em escola pública; e) a formação inicial e continuada não atende às expectativas dos professores.

As respostas de Ana demonstram que, de seu ponto de vista, poucos professores de inglês conseguem se comunicar oralmente na língua-alvo:

A fluência na língua estrangeira deveria ser uma regra para os professores de LEM, mas é a exceção à regra. Quando encontramos um professor fluente até os alunos ficam surpresos!

Temos muita indisciplina em nossas escolas, mas quando os alunos se deparam com um professor bem preparado, com sua aula planejada e com fluência na língua estrangeira, até seu comportamento e participação nas aulas muda. E quando é o contrário, o professor é motivo de piadas e a indisciplina está instalada.

A partir das palavras de Ana é possível evidenciarmos a crença de que um professor é considerado bom se é fluente na língua-alvo. Caso o professor de inglês não se comunique oralmente na língua que ensina, sua identidade profissional é questionada pelos estudantes, os quais não o consideram capaz de ensiná-los nesta disciplina. Ana afirmou ao responder ao questionário que "em sala de aula infelizmente usamos muito a língua materna para explicar as aulas de inglês". Para a pesquisada, esta é uma forma de o professor "ocultar sua deficiência na LE".

Daniela acredita que um dos motivos de haver tantos professores que não comunicamse oralmente em inglês é a não exigência de fluência como requisito para passar em um concurso. Considera que deveria ser um pré-requisito, visto que "o domínio da oralidade é para o professor de inglês como o domínio da pescaria para o pescador". Letícia também coloca a fluência como relevante ao postular que "não há mais como justificar que um professor de LI ensine a língua, mas não se comunique fazendo uso da mesma". Questiona o 
fato de os documentos que norteiam o ensino de línguas estrangeiras no estado do Paraná privilegiarem a leitura e a escrita em detrimento de outras habilidades.

A segunda crença que constatamos aponta que um professor fluente na língua que ensina demonstra domínio da disciplina e segurança aos alunos. Esta crença está diretamente relacionada à identidade profissional do docente, visto que a comunidade escolar passa a ter uma representação positiva do professor que utiliza a língua-alvo na forma oral. Por isso, abordaremos esta crença na seção sobre identidade profissional docente.

A terceira crença também está relacionada à identidade profissional docente porque se há desvalorização da disciplina o professor tende a não ser valorizado. De acordo com Paulo, "ainda há pouca valorização do trabalho com línguas nas unidades escolares. Temos uma cultura (histórico) muito pobre em relação a importância do aprendizado de línguas". Daniela evidencia que há uma "falta de reconhecimento de que o ensino de língua tem características especiais diferentes de outras matérias", o que de seu ponto de vista dificulta o trabalho do professor e contribui com a desvalorização da disciplina. A pesquisada ainda destaca que há um "descaso dos educandos e do sistema com a disciplina".

Sobre o ensino de inglês em escola pública, Ana faz a seguinte afirmação: "Diante da realidade, duas aulas semanais e quase $100 \%$ em língua materna, será impossível atingir a fluência". Está implícito nesta resposta que não haveria possibilidade de aprender a comunicar-se oralmente em língua inglesa. Ana considera que há diversos fatores que dificultam o sucesso do processo de ensino-aprendizagem da disciplina de inglês em escolas públicas: "Quando o professor tem a fluência em inglês, encontra algumas barreiras em sala de aula para trabalhar a oralidade: muitos alunos em sala de aula, indisciplina, desinteresse dos alunos, poucas aulas semanais". Daniela destaca como dificuldades enfrentadas em escolas públicas: salas lotadas, falta de recursos e também a desvalorização da disciplina pela comunidade escolar.

Por último, os participantes da pesquisa acreditam que tanto a formação inicial quanto a continuada não atendem às expectativas dos professores de inglês. Ana afirma que "a formação acadêmica é fraca e muitos não conseguem suprir esta deficiência sozinhos", "a formação continuada ofertada pelo estado é insuficiente, pois acaba sendo uma troca de experiências e estudo superficial de algumas teorias", "as formações são planejadas como se nossos professores não tivessem problemas de fluência e tivessem leitura de muitos teóricos, o que não é realidade". Percebemos que a maior preocupação de Ana é o fato de muitos professores de inglês não falarem a língua-alvo e não terem oportunidades de formação com foco na língua. Mesmo os professores precisando estudar mais a língua, as formações são direcionadas geralmente para discussões teóricas. Para Paulo, muitos professores não são fluentes em inglês como resultado de uma fraca formação acadêmica o que gera a necessidade de formação continuada: "Isto deve-se ainda a fraca formação acadêmica. É urgente uma melhor qualificação durante o ensino superior e também maior investimento na formação continuada, tipo o PDE (Programa de Desenvolvimento Educacional - PR) que é algo significativo". Ele considera ser possível preencher as lacunas na formação inicial se houver investimento em formação continuada de qualidade. 
Ao ser questionada a respeito de uma solução possível, Ana argumenta que "a única forma de sanar estas lacunas seria fazer uma formação continuada com encontros quinzenais e encontros de imersão com todos os professores de inglês". Paulo sugere que a situação pode ser melhorada "com mais política pública para o setor e despertar a necessidade da formação para os profissionais desta área". Letícia ainda ressalta que "os documentos que norteiam o ensino-aprendizagem de LI necessitam ser repensados, reorganizados e definidas estratégias coerentes com a realidade atual". Além da formação presencial com os professores, Letícia considera que alguns direcionamentos para a educação pública precisam ser repensados:

As DCEs [Diretrizes Curriculares Estaduais] elaboradas há quase uma década não priorizam a oralidade, dando ênfase às habilidades de leitura e escrita. Considerando o acesso à tecnologia, as relações sociais e o intercâmbio intercultural, faz-se necessário definir novas metas para o ensino de LI, bem como estabelecer estratégias para que se concretize as metas, equipando melhor as escolas e oportunizando capacitação aos professores desta área. Outro aspecto importante é que os documentos norteadores são elaborados por profissionais que não atuam na escola pública e não conhecem a realidade vivenciada diariamente (no caso das DCEs foram elaboradas por profissionais de universidades paranaenses, em especial da UFPR). A elaboração desses documentos necessitam ser elaborados em conjunto com os professores que atuam e conhecem a realidade e necessidades.

As crenças discutidas ao longo desta seção guiam as práticas dos docentes ainda que de forma inconsciente. Segundo Silva (2013), a forma como os professores veem o ensino acaba influenciando sua forma de pensar e trabalhar em sala de aula. Para Barcelos (2007), há uma relação de causa e efeito em que as crenças exercem influência direta nas ações. Neste caso, para que as ações sejam mudadas seria necessário mudar as crenças ou o processo inverso, mudar as crenças para modificar as ações.

Kudiess (2005) afirma que as mudanças de crenças podem ocorrer em sala de aula. A realidade da sala de aula faz com que o professor confronte suas crenças, fazendo com que esta seja confirmada, negada ou substituída por outra. As mudanças também ocorrem devido a leituras teóricas e com o tempo de experiência do professor. Em uma pesquisa realizada com professores, Kudiess constatou que as crenças que os professores adquiriram como aluno de língua estrangeira permanecem com eles e aquelas que adquiriram mais tarde através de outras experiências, como treinamento, prática docente, são mais passíveis de serem modificadas. As influências positivas que o professor teve como aluno, o que funcionou, ele mantém. Já as crenças negativas são substituídas. Kudiess concluiu a partir da pesquisa que:

Não é possível fazer grandes afirmações sobre como as crenças evoluem, mas o que se percebe é que estas, sempre que em contato com novas experiências, passam por um processo de "amadurecimento", seja através dos questionamentos dos professores, reflexões, conflitos, dúvidas ou simplesmente pela assimilação de novos conhecimentos, informações e aprendizagens, podendo vir a se transformar em outras crenças (sofrem mudanças) ou acomodar novas informações, fazendo com que os professores adaptem as suas crenças a uma situação específica (KUDIESS, 2005, p. 79). 
Por isso, é relevante que os professores de inglês passem por momentos de reflexão sobre as próprias crenças. Silva $(2007 ; 2013)$ defende que os cursos de formação de professores de línguas deveriam preparar os professores de maneira que saibam refletir sobre as próprias crenças e possibilitar-lhes repensar suas ações, pois eles podem não ter consciência das teorias que os norteiam em sala de aula e suas implicações para o ensino de línguas. Para Silva, o processo de reflexão sobre suas crenças levaria os professores a transformarem suas práticas em sala de aula. Da mesma forma, os professores deveriam estar aptos a lidarem com a diversidade das crenças em suas salas e prováveis conflitos que podem surgir entre suas próprias crenças e a de seus estudantes (BARCELOS, 2004). Barcelos (2004) defende que as crenças sejam inseridas no arcabouço teórico que faz parte da formação do profissional de línguas.

\section{Identidade profissional docente}

Barcelos (2004) estabelece uma relação entre aprendizagem de línguas, construção de identidade e crenças porque considera que somos aquilo em que acreditamos. Como vimos na seção anterior, as práticas docentes resultam inconscientemente de crenças, as quais, por sua vez, podem influenciar na identidade profissional do professor. Portanto, não é possível dissociar o processo de ensino-aprendizagem das crenças e da identidade docente.

As transformações sociais, culturais e econômicas ocorridas nas últimas décadas desestabilizaram as identidades dos sujeitos. “(...) as velhas identidades, que por tanto tempo estabilizaram o mundo social, estão em declínio, fazendo surgir novas identidades e fragmentando o indivíduo moderno, até aqui visto como um sujeito unificado" (HALL, 2006). Este processo impossibilita abordar atualmente apenas uma identidade, pois é preciso considerar que as pessoas possuem identidades no plural, de acordo com os grupos nos quais estão inseridas e os contextos. Para Hall (2006), a identidade é definida historicamente, e não biologicamente, por isso está continuamente sendo formada e transformada.

Figueiredo e Noronha (2010, p. 189) consideram que a identidade "designa algo que se assemelha à percepção que as pessoas têm de si mesmas e das características fundamentais que as definem como seres humanos. A tese é que nossa identidade é parcialmente formada pelo reconhecimento ou pela ausência dele (...)". O modo como nos vemos influencia em nossa identidade, mas nossa identidade não depende apenas de como nos vemos, também depende de como os outros nos veem.

Com base em Garcia, Hypolito e Vieira (2005), entendemos por identidade profissional docente as posições de sujeito que são atribuídas, por diferentes discursos, aos professores e às professoras atuando em contextos concretos de ensino. Seriam as representações sobre os modos de ser e agir de professores atuando na educação que circulam entre as pessoas da comunidade escolar. Além disso, abrange também as representações que os docentes fazem de si mesmos. Os diversos fatores que estão relacionados às identidades profissionais dos docentes resultam da história de vida de cada um, da formação, das condições de trabalho, do imaginário recorrente acerca dessa profissão 
A identidade profissional de um professor de língua inglesa passa por um processo de formação, na formação inicial, e de desenvolvimento, a partir do momento em que o professor começa a atuar, e se prolonga por toda a carreira. Sendo assim, a construção de uma identidade profissional é um processo de socialização e amadurecimento (DEMIREZEN, 2007). A identidade profissional de um professor começa a receber influências na formação inicial, seja de professores, de teorias, de colegas, está em constante processo de construção, pelo fato de o professor estar sempre aprendendo e estudando, e de reconstrução, pelo fato de rever suas práticas e procurar modificá-las quando necessário.

A constante busca por uma identidade é resultado da fragmentação vivenciada após diversas transformações sociais, culturais e econômicas que tornaram a identidade algo instável, inacabado. Tal instabilidade propicia o surgimento de uma crise identitária: a incerteza a respeito de quem é, qual é o seu papel. Um professor entra em crise de identidade profissional no momento em que deixa de estar satisfeito com a sua representação social, ou seja, a maneira como as pessoas o veem e o modo que vê a si mesmo. Significações e imagens que o professor de inglês projeta de si entram em choque com a forma como os outros o veem (VÓVIO, 2007). Críticas ouvidas ao longo da carreira contribuem para o estado de crise identitária e o questionamento da própria identidade profissional.

Há diversos fatores que podem causar uma crise de identidade profissional docente: condições de trabalho, comunidade escolar, baixo reconhecimento, baixo salário. Para Gomes (2008) devemos olhar além do espaço de trabalho do professores. Segundo o autor, os fatores apontados não são os únicos indicadores para analisarmos uma suposta crise de identidade profissional do professor. Há outros indicadores a serem considerados, como crenças, valores éticos e morais, representações construídas/adquiridas sobre ser professor. São todos fatores que repercutem direta e significativamente na atuação docente. Além disso, Gomes (2008) ainda sugere considerar as políticas públicas e a ação do Estado como implicações para a construção de identidade profissional e sua crise.

Todos os fatores citados e outros não mencionados sugerem o que é esperado de um professor de inglês. A crise surge ao haver uma "(...) oposição entre o que esperam que o sujeito assuma e seja e o desejo do próprio sujeito em ser e assumir determinadas identidades" (FARIA; SOUZA, 2011, p. 37). No caso, as representações da sociedade podem ser contrárias ao que o professor deseja assumir, ocasionando a crise de identidade. No decorrer do processo contínuo de formação de identidade, a crise pode ser minimizada ou agravada, dependendo das decisões tomadas pelo próprio docente.

Os dados coletados junto aos participantes da pesquisa mostraram que o principal motivo para o questionamento da identidade profissional do professor de inglês é a falta de fluência na língua ensinada, o que evoca a crise identitária. Segundo os pesquisados, o domínio da língua é considerado pela sociedade, de modo geral, o mais importante para um professor de língua inglesa, ficando em segundo plano conhecimento teórico-metodológico. Por isso, os participantes sentem a necessidade de aprimorarem o conhecimento de língua inglesa, principalmente a oralidade, e inscreveram-se no curso. Como o curso foi desenvolvido na língua-alvo, alguns professores desistiram ao longo dos encontros. Para Ana isso demonstra "a deficiência de muitos colegas que se sentiram constrangidos e não quiseram participar para não se expor". Esta fala evidencia que a identidade do professor de inglês é questionada se ele não consegue utilizar a língua que ensina na forma oral. 
De acordo com Fernandes (2006, p. 3), "os professores abdicam de suas identidades por se compararem a um modelo cultural e socialmente aceito como ideal: o falante nativo". Apesar de avanços nos estudos de Linguística Aplicada, o falante nativo ainda é visto como modelo a ser seguido pela maior parte da sociedade brasileira (estudantes e pais) e até mesmo por professores de línguas. Este fator foi o que ficou mais evidente nas respostas dos questionários. Atrelado a isso está a visão recorrente de que um professor fluente em inglês demonstra segurança e confiança aos estudantes em sala de aula, como nos trechos a seguir:

Como a formação do professor não garante o domínio da LI o professor que dominar vai se sentir mais seguro e isso já vai melhorar muito sua autoestima e seu relacionamento com os alunos. (Ana)

Ao saber falar, demonstrar uma pronúncia boa, o profissional passa segurança aos estudantes e motiva-os ao estudo desta língua. Isto é fundamental nesta disciplina. (Paulo)

Domínio de conteúdo traz segurança o que faz com que o aluno confie no que lhe está sendo ensinado. (Daniela)

Mencionamos anteriormente que os professores participantes da pesquisa afirmaram que a disciplina de inglês é desvalorizada pela comunidade escolar. O confronto da visão dos professores com a de pais, estudantes e colegas de trabalho pode gerar alguns conflitos por causa das diferentes opiniões. Como veremos na resposta de Ana, a fluência na língua-alvo é apontada tanto como geradora de conflitos e de crise identitária quanto como a solução para o questionamento da identidade profissional do professor de inglês.

Os professores em geral não são valorizados no Brasil. O professor de língua estrangeira é desvalorizado até pelos colegas de outras áreas em sua própria escola. A partir do momento que o professor tiver a fluência ele se sentirá seguro, irá ensinar melhor seus alunos e será respeitado por seus colegas, pais de alunos e etc. Temos muito o que melhorar na educação no Brasil. Quando sair dos discursos eleitorais e implementarem nas escolas será o início da grande mudança.

Ana enfatiza o questionamento da identidade profissional do professor de inglês, ao mesmo tempo que mostra como, segundo seu ponto de vista, seria possível ganhar o reconhecimento: fluência oral na língua-alvo. Letícia também considera que este seja o caminho para a valorização da disciplina e do docente: "Assim como os educandos percebem no professor de LI sua capacidade na oralidade os demais professores e a direção também valorizam e respeitam o profissional". Paulo apresenta o mesmo ponto de vista, considerando que com um professor fluente os estudantes "sentem-se motivados e conseguem desenvolver seu potencial”, “já um(a) professor(a) que não domina a língua terá limitações em sua atuação pedagógica, resultando em déficit para os estudantes".

A palavra "segurança" foi empregada por todos os participantes para demonstrarem uma representação de professor que afirma sua identidade profissional docente. Percebemos 
que os participantes buscam o reconhecimento e apontam a falta de fluência oral da maioria dos professores atuantes como fator chave na existência de uma má representação profissional de professores de inglês. O professor de inglês ideal para este grupo é aquele que utiliza a língua inglesa oralmente. Outros aspectos relevantes como didática e metodologia não foram destacados pelos participantes. Constatamos que provavelmente os principais conflitos que enfrentam na escola pública estejam relacionados à fluência e lembramos falas recorrentes no Brasil como: "os alunos não aprendem inglês em escola pública"; "os professores de inglês dão aula em português"; "os alunos não sabem nem português".

\section{Considerações finais}

A interpretação dos dados coletados evidenciou que há um entrelaçamento entre crenças, identidade profissional e conflitos que surgem no contexto escolar. Nesta pesquisa a fluência em língua inglesa é apontada como importante para a prática do professor de inglês e fator gerador de conflitos visto que as crenças e expectativas da comunidade escolar (pais, estudantes, colegas de trabalho) com relação à proficiência do professor nem sempre condizem o que o professor ensina.

O estudo das crenças é relevante visto que faz a mediação do processo de ensinoaprendizagem em sala de aula, ainda que o professor não tenha consciência disso. $\mathrm{O}$ fato de os participantes da pesquisa apontarem a oralidade como primordial para um professor de inglês demonstra que suas escolhas e ações como docentes poderão estar relacionadas à oralidade. Os participantes também mostram que gostariam que outros profissionais professores de inglês se dedicassem mais ao estudo da língua-alvo, o que geraria uma mudança na forma de ensinar a língua. A formação continuada poderia gerar mudanças nas ações dos professores, as quais mudariam suas crenças ou a mudança nas crenças poderia motivar mudanças nas ações.

Das crenças apontadas, a mais recorrente entre os participantes é a que um professor fluente em inglês demonstra segurança. Esta crença é uma motivadora da crise de identidade profissional docente, pois as pessoas da comunidade escolar tendem a questionar a identidade profissional do professor de inglês que não demonstra domínio oral da língua. Outros fatores que afetam a identidade do professor é a desvalorização do ensino da língua inglesa e a crença de que é impossível aprender inglês em escola pública, resultando em um pessimismo entre os envolvidos no processo de ensino-aprendizagem que amplia os conflitos nas aulas de inglês.

Sendo que a identidade do professor é algo vivo e mutável, a formação continuada é um ponto relevante. Para os pesquisados, a formação continuada pode contribuir com a (re)construção da identidade profissional. Para além das discussões teóricas, os professores participantes indicam a fluência oral como essencial para o reconhecimento profissional, tanto no meio escolar quanto na sociedade. Em suas respostas ao questionário, demonstram que a fluência oral é fator positivo na constituição da identidade profissional do professor de Língua Inglesa, ou seja, ao falar inglês o docente reafirma sua identidade diante da comunidade escolar; por outro lado, a falta de fluência contribui para a crise de identidade profissional do docente e muitas vezes no fracasso da eficácia do processo do ensino de língua inglesa. Concluímos a partir dos dados que mais oportunidades de formação continuada com foco na prática da oralidade e da compreensão oral contribuiriam para afirmar a identidade profissional do professor de inglês. Os participantes ressaltam que a sociedade, de modo 
geral, ainda julga o professor de Língua Inglesa em comparação ao falante nativo, ou seja, alunos, pais e colegas de trabalho acreditam que o mais relevante é o professor de inglês falar a língua-alvo fluentemente, sem considerar que um professor de línguas deve ter uma formação inicial e continuada adequada, que possibilite o conhecimento teórico e metodológico para ensinar uma língua estrangeira no contexto brasileiro.

\section{Referências}

BARCELOS, A. M. F. Metodologia de pesquisa das crenças sobre aprendizagem de línguas: Estado da arte. Revista Brasileira de Linguística Aplicada, v. 1, n. 1, p. 71-92, 2001.

BARCELOS, A. M. F. Crenças sobre aprendizagem de línguas, Linguística Aplicada e ensino de línguas. Linguagem \& Ensino, v. 7, n. 1, p. 123-156, 2004.

DEMIREZEN, M. Identity problems of non-native teachers of English in teacher education. The Internet TESL Journal, v. 13, n. 8, august 2007. Disponível em: < http://iteslj.org/Articles/Demirezen-NonNativeTeachers.html>. Acesso em: 13 set. 2013.

FARIA, E.; SOUZA, V. L. T. Sobre o conceito de identidade: apropriações em estudos sobre formação de professores. Revista Semestral da Associação Brasileira de Psicologia Escolar e Educacional, São Paulo, v. 15, n. 1, p. 35-42, jan./jun., 2011.

FERNANDES, C. S. Representações e construção da identidade do professor de inglês. 2006. Dissertação (Mestrado em Linguística Aplicada e Estudos da Linguagem). Pontifícia Universidade Católica de São Paulo, São Paulo. 2006.

FIGUEIREDO, E.; NORONHA, J. M. G. Identidade nacional e identidade cultural. In: FIGUEIREDO, E. Conceitos de literatura e cultura. 2. ed. Niterói: EdUFF; Juiz de Fora: EdUFJF, 2010, p. 189-205.

GARCIA, M. M. A.; HYPOLITO, A. M.; VIEIRA, J. S. As identidades docentes como fabricação da docência. Educação e Pesquisa, São Paulo, v. 31, n. 1, p. 45-56, jan./abr. 2005.

GOMES, A. A. A construção da identidade profissional do professor: uma análise de egressos do curso de Pedagogia. In: Congresso Português de Sociologia, 6, 2008, Lisboa. Anais eletrônicos... Lisboa, Universidade Nova de Lisboa, 2008. Disponível em: <http://www.aps.pt/vicongresso/pdfs/590.pdf>. Acesso em: 10 set. 2013.

HALL, S. A identidade cultural na pós-modernidade. 11. ed. Rio de Janeiro: DP\&A, 2006.

KUDIESS, E. As crenças e os sistemas de crenças do professor de Inglês sobre o ensino e a aprendizagem da língua estrangeira no sul do Brasil: sistemas, origens e mudanças. Linguagem \& Ensino, v. 8, n. 2, p. 39-96, 2005.

LIMA, F. S. Em defesa da aprendizagem de inglês na escola pública: considerações sobre crenças de alunos adolescentes. Uniletras, Ponta Grossa, v. 34, n. 2, p. 157-170, jul/dez. 2012.

QUADROS, A. L. et al. Professor em início de carreia: relato de conflitos vivenciado. Revista Varia Scientia, v. 6, n. 12, p. 69-84, 2006. 
SILVA, K. A. Crenças sobre o ensino e aprendizagem de línguas na Linguística Aplicada: um panorama histórico dos estudos realizados no contexto brasileiro. Linguagem \& Ensino, v.10, n.1, p. 235-271, jan./jun., 2007.

SILVA, K. A. Linguística aplicada, crenças e formação de professores na contemporaneidade. In: SANTOS, L. I. S.; SILVA, K. A. (Orgs.). Linguagem, ciência e ensino: desafios regionais e globais. Campinas, SP: Pontes Editores, 2013. p. 19-40.

SILVA, J. O. Propagandas do MEC: imagens da profissão docente. In: REIS, S.; VEEN, K.; GIMENEZ, T. (Orgs.). Identidades de professores de línguas. Londrina: Eduel, 2011. p. 107-119.

VÓVIO, C. L. Entre discursos: sentidos, práticas e identidades leitoras de alfabetizadores de jovens e adultos. Campinas, SP: 2007. 